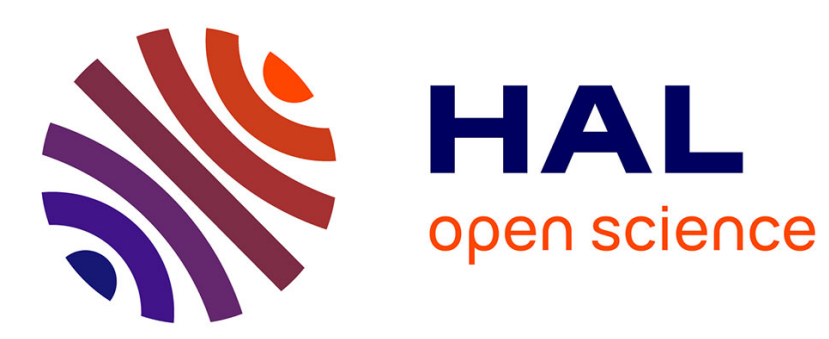

\title{
ORIGIN OF COBALT ANISOTROPY IN RARE EARTH-COBALT INTERMETALLICS
}

\author{
Rafik Ballou, R. Lemaire
}

\section{To cite this version:}

Rafik Ballou, R. Lemaire. ORIGIN OF COBALT ANISOTROPY IN RARE EARTHCOBALT INTERMETALLICS. Journal de Physique Colloques, 1988, 49 (C8), pp.C8-523-C2-524. 10.1051/jphyscol:19888237 . jpa-00228402

\section{HAL Id: jpa-00228402 https://hal.science/jpa-00228402}

Submitted on 1 Jan 1988

HAL is a multi-disciplinary open access archive for the deposit and dissemination of scientific research documents, whether they are published or not. The documents may come from teaching and research institutions in France or abroad, or from public or private research centers.
L'archive ouverte pluridisciplinaire HAL, est destinée au dépôt et à la diffusion de documents scientifiques de niveau recherche, publiés ou non, émanant des établissements d'enseignement et de recherche français ou étrangers, des laboratoires publics ou privés. 


\title{
ORIGIN OF COBALT ANISOTROPY IN RARE EARTH-COBALT INTERMETALLICS
}

\author{
R. Ballou and R. Lemaire \\ Laboratoire Louis Néel, C.N.R.S., 166 X, 38042 Grenoble Cedex, France
}

Abstract. - The strong cobalt anisotropies in rare earth-cobalt intermetallics are shown to arise from orbitally selective $3 \mathrm{~d}$ band energy dispersion due to either chain like or layered like cobalt staking rather than from usual crystal field effect.

The magnetic anisotropies of itinerant electron systems are difficult to study in a complete theoretical model due to the great complexity of the collective character of the electronic states. As opposed to the case of insulators where the crystal field concept has revealed to be a usefull tool to get deep insight, a rigorous approach for itinerant systems demands indeed the prohibitive task of band structure calculations taking into account spin-orbit coupling. So far, one is led to adopt a rather phenomenological point of view, trying to find out through different clear-cut experimental situations the gross features of the relevant parameters.

A phenomenological approach is to consider the spin-orbit coupling as a perturbation on the band Hamiltonian, and to expand energy and magnetization as power series of the components of the magnetization vector with respect to the crystallographic axes. These expansions define the magnetization and the energy anisotropy constants, the sign and magnitude of which are attached to the orbital selection operated on the collective electron states before the spin-orbit coupling is switched on. Such a selection has two origins: the first one is analogous to what occurs in insulators and corresponds to the diagonal elements of the band Hamiltonian in the individual state representation. The second, properly itinerant, is due to the multi-centre resonance integrals, mixing the individual states and leading to the electron energy dispersion. A strong dependence of this dispersion on the azimuthal quantum number is to be expected for an atomic packing other than the compact ones. According to this dependence, usual crystal field effects may then become less efficient. We report in this paper on a study of the magnetic anisotropy in the $\mathrm{RCo}_{1-\varepsilon}$ (R: la, $\mathrm{Pr}$, $\mathrm{Nd}$ ) compounds which illustrate the extreme case of a quasi-linear atomic packing.

The $\mathrm{RCo}_{1-\varepsilon}$ compounds crystallize in an original structure [1]: $\mathbf{R}$ atoms form a ABAB type of hexagonal packing while Co atoms are found in chains along the 6-fold axis. The Co-Co distance within a chain is more than two times smaller than the distance between chains and is incommensurate with the lattice parameter along the 6-fold axis of the $\mathrm{R}$ sublattice. As a con- sequence, correlations in Co positions between chains are weak. They are described in terms of a propagation vector $[\tau \tau$ 0] where $\tau$ reaches, for instance, a value of 0.112 in $\mathrm{LaCo}_{1-\varepsilon}$. All this information outlines the strong linear character of the cobalt packing.

As reported earlier [2], a triangular antiferromagnetic order is observed in $\mathrm{LaCO}_{1-\varepsilon}$ whereas $\mathrm{PrCO}_{1-\varepsilon}$ and $\mathrm{NdCO}_{1-\epsilon}$ exhibit a collinear ferromagnetism at low temperature. We show in figure 1 the thermal

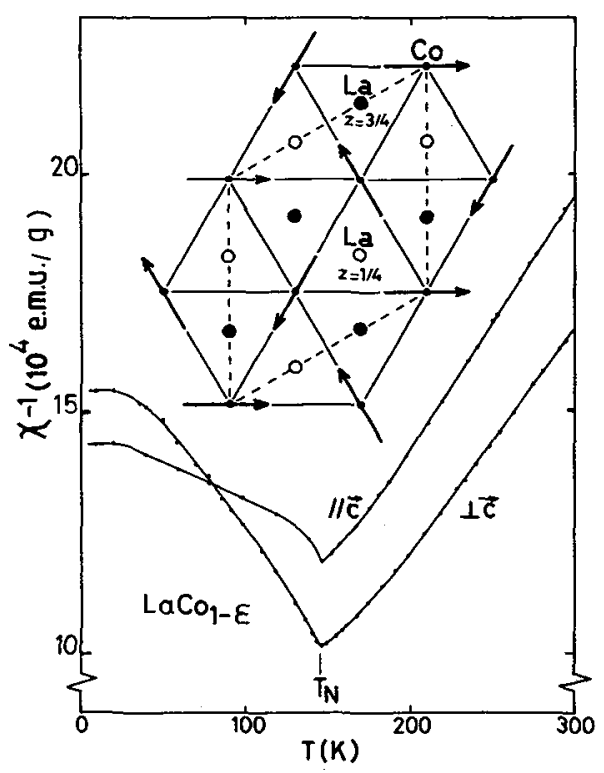

Fig. 1. - Thermal variation of the reciprocal susceptibility in field parallel and perpendicular to the chain axis $c$ as well as the magnetic structure of $\mathrm{LaCO}_{1-\varepsilon}$.

variation of the reciprocal susceptibility measured in a $\mathrm{LaCO}_{1-\epsilon}$ single crystal in fields parallel and perpendicular to the chain axis. A large anisotropy favouring the basal plane perpendicular to the chain axis is evident. Above the Néel temperature $\left(T_{N}=146 \mathrm{~K}\right)$ the susceptibility follows a Curie-Weiss law of the form 
$\chi_{0}+C /(T-\theta)$ where $\chi_{0}$ is negative and equals $-2.2 \times$ $10^{-6} \mathrm{emu} / \mathrm{g}$. The Curie temperature $\theta$ reaches a value of $-295 \mathrm{~K}$ and $-246 \mathrm{~K}$, respectively in fields parallel and perpendicular to the chain axis. Such a shift accounts for a cobalt anisotropy energy amounting to $49 \mathrm{~K}$ per cobalt atom. We show also in figure 2 the magnetic isotherms measured at $4.2 \mathrm{~K}$ in a $\mathrm{PrCo}_{1-\varepsilon}$ single crystal for different orientations in field. A large anisotropy favouring the basal plane perpendicular to the chain axis is observed. In this case it results from both praseodymium and cobalt contributions. A fit of the experimental isotherms has been tried assuming crystal field effects on $\mathrm{Pr}^{3+}$ ions only. A discreapency always persists between the calculated and observed isotherms in field parallel to the chain axis (see Fig. 2). It accounts for a large cobalt anisotropy by which the basal plane perpendicular to the chain axis is favoured. Similar conclusions are drawn from the $\mathrm{NdCo}_{1-\varepsilon}$ data.

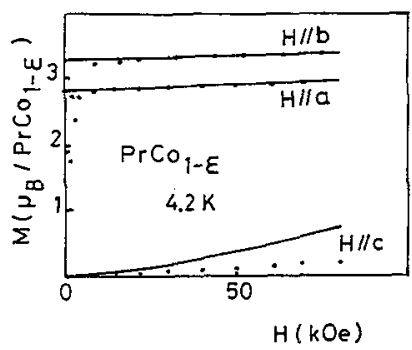

Fig. 2. - Magnetic isotherms measured at $4.2 \mathrm{~K}$ in a $\mathrm{PrCO}_{1-\varepsilon}$ single crystal in fields suscessively parallel to the $a([100]) b([120])$ and $c([001])$ axis of the underlying orthohexagonal cell of the structure. Solid lines stands for the best fit assuming only crystal field effects on $\mathrm{Pr}^{3+}$ ions.

In order to confirm the large cobalt anisotropy NMR studies on the three compounds have also been performed [3]. The observed cobalt hyperfine fields are positive reaching up to $52 \mathrm{kOe}$ in $\mathrm{LaCO}_{1-\varepsilon}$ which leads relative contributions of $70 \%$ and $30 \%$ for the spin and orbital contribution to the cobalt moment, respectively. This cobalt orbital magnetism is at the origin of the cobalt magnetic anisotropy.
In conclusion, large cobalt anisotropies are observed in the $\mathrm{RCO}_{1-\varepsilon}$ compounds. They must be associated to the cobalt chain like stacking. Indeed, resonance integrals are preponderant only along the chains. This results in an important energetic dispersion of the prolate states whereas the oblate states, perpendicular to the chain axis, are populated in a narrow energy window. This orbital selection is larger than the crystal field effects and as the Fermi level in cobalt is at the top of the $3 \mathrm{~d}$ band, cobalt magnetism is essentially characterised by the prolate states. The application of spin orbit coupling leads then to a strong basal plane anisotropy. Such an orbital selection through resonance integrals plays also a role in the $\mathrm{RCo}_{5}(\mathrm{R}=$ $Y$, Th or a rare earth) intermetallics and is in agreement with the high uniaxial cobalt anisotropy in these compounds [4]. In this case the cobalt chemical bonds have a strong planar character, in particular the R-Co bond for the cobalt atoms at the site $2 \mathrm{c}$ which hold the largest anisotropy [5]. This latter bond enhances the dispersion of the oblate states through the $3 \mathrm{~d}-5 \mathrm{~d}$ hybridization. Since the Fermi level is again at the top of the $3 \mathrm{~d}$ band, the cobalt magnetism is associated to these oblate states. The spin-orbit coupling induces then an anisotropy favouring the 6-fold axis of the structure.

[1] Schweizer, J., Strnat, K. A., Tsui, J., 9th Rare Earth Res. Conf., Blacksburg, Virginia, U.S.A. (1981).

[2] Ballou, R., Gignoux, D., Lemaire, R., MendiaMonterroso, R., Schweizer, J., J. Magn. Magn. Mater 54-57 (1986) 499.

[3] Ballou, R., Lemaire, R., to be published.

[4] Alameda, J. M., Givord, D., Lemaire, R., Lu, Q., J. Appl. Phys. 52 (1981) 2079.

[5] Schweizer, J., Tasset, F., J. Phys. F 10 (1980) 2799. 